\title{
Anger Expression, Emotion Regulation and Mindfulness as Predictors of Conduct Problems in Children
}

\author{
Dr. Mandy Roeder, \\ Dr. Anna R. Mueller, \\ Goethe-Universitaet Frankfurt am Main,Germany
}

Doi:10.19044/esj.2019.v15n22p1 ～URL:http://dx.doi.org/10.19044/esj.2019.v15n22p1

\begin{abstract}
Conduct problems and aggressive behaviors of children are serious problems for peers, parents and teachers of these children. To improve the understanding of conduct problems the present study investigates the links between difficulties in anger expression, emotion regulation, difficulties in impulse control and conduct problems. Moreover the relation of mindfulness and emotion regulation was of interest in the present study. To answer our research questions 310 elementary school children (157 boys, 153 girls) and their parents reported anger expression, emotion regulation strategies, mindfulness and conduct problems in a questionnaire. The results revealed that mindfulness was significantly related to anger expression and conduct problems. Moreover a regression analysis showed that anger expression mediated the relation of mindfulness and conduct problems. Child and parent reports were only weakly related if anger expression strategies that are hardly observable (Anger In, Anger Control) were considered. Relations were somewhat stronger for Anger Out. The findings are discussed and the relevance of mindfulness based emotion regulation is highlighted. The findings support the assumption that mindfulness, anger expression and emotion regulation are important aspects that influence child behavior.
\end{abstract}

Keywords: Emotion regulation, Elementary school, Mindfulness, Conduct problems, Anger

\section{Introduction}

Hardly any topic received as much interest as conduct problems and aggressive behaviors of children (Holtappels, Heitmeyer, Melzer, \& Tillmann, 2009). The distress resulting from aggressive behaviors illustrates that it is important to analyze the development and emergence of aggressive behaviors. Conduct problems or aggressive behavior are often related to difficulties in 
impulse control and anger regulation (Cole, Zahn-Waxler, Fox, Usher, \& Welsh, 1996). It has recently been argued by different authors, that mindfulness enhances emotion regulation and that mindfulness can be helpful in the treatment of anger problems (Hill \& Updegraf, 2012; Teper, Segal, \& Inzlicht, 2013; Wright, Day, \& Howells, 2009). Mindfulness can be described as a characteristic of a person that is related to his or her psychological state (Hill \& Updegraff, 2012). Kabat-Zinn (1994) was one of the first authors suggesting two major aspects of mindfulness: 1) paying attention to one's own feelings, actions and sensations in the present moment and 2) accepting these without judging (Teper et al., 2013). Mindfulness was included in several psychotherapy concepts that were found to be effective in reducing negative emotional states (e.g., Evans et al., 2008; Ma \& Teasdale, 2004) and there are also promising effects of programs that use mindfulness when treating externalizing behavior or conduct problems of children (Lee, Semple, Rosa, \& Miller, 2008).

Due to the high importance of emotions and emotion regulation for school success, well-being and social integration (Eisenberg, Spinrad, \& Eggum, 2010; Harnett \& Dawe, 2012) the present study sought to examine the relationship of anger expression, emotion regulation, mindfulness and conduct problems in children.

\section{Emotions, Emotion Regulation and Emotion Expression}

Emotions help to organize social interactions and they can motivate rapid reactions of approach or avoidance as response to a situation (Izard, 2009). Many mental processes are involved in the perception and experience of emotions (Petermann \& Wiedebusch, 2008). Due to the conception of emotions as a range of mental states, it can be assumed that different individual characteristics (e.g., mindfulness) can shape the experience of emotions (Hill \& Updegraff, 2012).

In their development, children make progress in their abilities to understand, express and regulate emotions in social situations (Petermann \& Wiedebusch, 2008). It was demonstrated that school aged children possess a variety of emotion regulation strategies that can be used adaptively in different situations (Stegge \& Meerum Terwogt, 2007). According to the Process Model of Emotion Regulation (Gross, 2002), a response-focused regulation of emotions includes the regulation of behavior, physiological responses and the expression of emotions. With respect to conduct problems of children anger is an emotion that is very important. From previous research it is well known that children can express anger in different ways. Kerr and Schneider (2008) conducted a review of the empirical literature and distinguished between ways to hide or show anger. The authors described that depending on situation and individual characteristics children could hide their anger, show it outwardly or 
repress their anger. Moreover, Kerr and Schneider (2008) highlight that children do not always express their anger in the intensity that it is felt, because they are able to regulate it. Therefore the relation of anger expression, emotion regulation and mindfulness in children is a very interesting research topic.

\section{The Relationship of Mindfulness and Emotion Regulation}

A number of studies demonstrated a strong positive relation between mindfulness and emotion regulation in adolescents or adults (e.g., Hill \& Updegraff, 2012; McLaughlin, 2010; Teper et al., 2013). Most theories propose that mindfulness influences emotion regulation, but there are differences in the suggested mechanisms of that influence. For example, Linehan (1993) as well as Kabat-Zinn et al. (1992) argued that mindfulness exposes people to their emotions and therefore helps people to cope with their emotions. Furthermore, Linehan (1993) argued that mindfulness can change cognitive patterns by focusing attention toward feelings and sensations in the actual moment rather than ruminating about things that have happened in the past or might happen in the future. This cognitive change may then influence emotion regulation. A third theory concerns self-management skills. Baer (2003) suggested that mindfulness might improve the early detection of mood swings that can then easier be handled. Another idea was proposed by Teper et al. (2013). The authors argued that mindfulness enhances the sensitivity to changes in the emotional state of the individual person. In that way, already subtle changes can be detected and signal a need for executive control.

Taken together, it seems as though mindfulness affects emotion regulation in many ways and that both (mindfulness and emotion regulation) are related to positive behavioral outcomes whereas a lack of mindfulness and emotion regulation are related to negative behavioral outcomes. Taken together, research has shown that mindfulness and emotion regulation are important predictors of a healthy social and academic development, but they are not always easy to measure.

\section{Measurement of Mindfulness, Anger Expression, Emotion Regulation and Conduct Problems}

Mindfulness is usually measured by self-report (Baer, Smith, Hopkins, Krietemeyer, \& Toney, 2006). Greco, Baer, and Smith (2011) introduced a questionnaire to assess mindfulness in children. The Child and Adolescent Mindfulness Measure (CAMM; Greco et al., 2011) can be used for children in elementary school age and comprises 10 items that have to be answered by the children. In the present study the suitability of this measure for German children will be explored. In addition to mindfulness ways to express anger were of interest in the present study. Kerr and Schneider (2008) introduced different measures assessing anger expression. Most of the instruments that 
were presented in their study relied on children's self-reports. This seems to be the best way to assess anger expression tendencies as only self-reports may cover the tendency to hide or repress anger.

For emotion regulation, on the other hand, there are self-reports for children (e.g., CERQ; Garnefski et al., 2007; ERICA; MacDermott et al., 2010) as well as ratings of parents or teachers (ERC; Shields \& Cicchetti, 1997) available. The reports of parents and children do usually only show medium levels of correspondence (van der Ende, Verhulst, \& Tiemeier, 2012). Nonetheless, child as well as parent reports contribute important information for the prediction of conduct problems. To measure conduct problems selfand parent-report measures are available as well, that can be chosen depending on the research setting.

\section{Goals of the Present Study}

The present contribution had two major goals. A major aim of the study was to investigate the dimensional structure and reliability of German versions of three instruments that can be used in the research of mindfulness, anger expression and emotion regulation. While there are several instruments available in the international research literature to measure those constructs, German instruments to assess mindfulness, anger expression and emotion regulation in children are rare. For that reason, one goal was to analyze the properties of the Emotion Regulation Checklist (ERC; Shields \& Cicchetti, 1997), the Child and Adolescent Mindfulness Measure (CAMM; Greco et al., 2011), and the child version of the State-Trait-Anger-Expression Inventory (STAXI; Seip, 2010).

After the scales were analyzed the relationship between mindfulness ratings of children, their anger expression, emotion regulation and conduct problems should be investigated. It was hypothesized that children with higher levels of mindfulness would show lower levels of conduct problems and higher levels of emotion regulation skills. With respect to anger expression it was expected that children with higher levels of mindfulness would show less hiding and less repression of anger.

\section{Method \\ Sample}

The complete sample consisted of 310 children (157 boys, 153 girls) from elementary schools in Germany. The schools were asked to hand consent forms to the parents of the children. There were no rewards for the participation and no negative consequences if the parents declined to participate. It was assured to all participants that the participation in the study was voluntary and that the collected data would be treated in accordance with provisions. The children were between 8 and 12 years of age and the mean age 
of the children was 9.05 years $(S D=0.81$ years). Children were attending the third or fourth grade. All children received a questionnaire for their parents but only 201 questionnaires were sent back to us by the parents. Therefore, parental data are only available for these children and it was decided to use only datasets with data from parents and children. Therefore the final sample consisted of 201 children (94 boys, 107 girls) with a mean age of 9.07 years $(S D=0.83$ years $)$.

The data of children who were included in the final sample did not differ from the data of children who were not included in the final sample with respect to anger expression and mindfulness (all $t$-tests comparing both groups were not significant, $p s>.05)$.

\section{Material}

\section{Anger Expression}

To assess anger expression in children the German version of the child version of the State-Trait-Anger-Expression Inventory (STAXI-CA; Seip, 2010) was used. The STAXI (Schwenkmezger, Hodapp, \& Spielberger, 1992) assesses different forms of anger expression. The questionnaire distinguishes between three forms of anger expression: Anger In, Anger Out and Anger Control. The subscale Anger In assesses strategies to hide the anger that a person is feeling and to withdraw from other people if one is feeling angry. The subscale Anger Out in contrast assesses anger expression in form of verbal or physical reactions. The Anger Control subscale assesses strategies to control anger with the help of cognitive efforts. The authors of the questionnaire argue that very high levels on this scale might indicate a dysfunctional anger expression. The original STAXI (Schwenkmezger et al., 1992) was developed for adults. In the present study a version that has been reformulated by Seip (2010) has been used. The child version of the STAXI that has been used in this study comprises 29 items that had to be answered on a three-point scale ranging from 1 (not true) to 3 (true). A sample item reads: "When I am angry, I yell at others." (Anger Out).

\section{Mindfulness}

Children's mindfulness was assessed with the Children's Acceptance and Mindfulness Measure (CAMM; Greco et al., 2011). The questionnaire comprises 10 items that had to be answered on a five-point scale from 1 (never) to 5 (always) and measures mindfulness in children and adolescents. A sample item reads: "I keep myself busy so I don't notice my thoughts or feelings." (inverse coded item). Higher values on this scale indicate a higher level of mindfulness. 


\section{Strength and Difficulties Questionnaire}

All parents were asked to complete a German version of the Strength and Difficulties Questionnaire (SDQ; Woerner et al., 2002) in order to rate the behavioral difficulties of the child. For the present study only the scale "conduct problems" of the SDQ is reported. The scale comprises 5 items, which have to be rated on a 3-point Likert scale ranging from 0 (not true) to 2 (certainly true). A sample item reads: "My child often has temper tantrums or hot temper."

\section{Emotion Regulation Checklist}

Parents were also asked to complete the Emotion Regulation Checklist (ERC; Shields \& Cicchetti, 1997). The ERC is a 24-item measure assessing children's emotional self-regulation abilities. The items had to be answered on four-point scales from 1 (never) to 4 (always). The ERC contains two subscales: lability / negativity (15 items) and emotion regulation ( 8 items) and one item is not used for the formation of the scales. A sample item of the emotion regulation scale reads: "[My child] can recover quickly from episodes of upset or distress." The emotion regulation subscale of the ERC assesses processes that are central to an adaptive regulation, including socially appropriate emotional reactions and empathy. The lability / negativity scale assesses arousal, reactivity, anger regulation, and mood lability.

\section{Procedure}

Written active informed consent was obtained from the parents prior to the data collection. All children were verbally asked for their assent to participate in the study before they participated. Permissions from the Hessian Ministry of Education and the Arts and the school authorities were gathered prior to the onset of the study.

The children were visited during normal class hours in their schools and they were asked to fill in the questionnaires. After the children had completed the questionnaires, a questionnaire for their parents was handed to them. Parents were asked to fill in the scales and to return the questionnaires to the school were a member of the research group collected them.

\section{Results}

\section{Dimensionality of the Scales}

In a first step, the factorial structure of the child version of the STAXI was analyzed with a confirmatory factor analysis using Amos (Arbuckle, 2013). The original German version of the STAXI (Schwenkmezger et al., 1992) contains three dimensions. These are 1) showing anger to other people (Anger Out), 2) hiding anger (Anger In) and 3) regulating anger (Anger Control). Therefore a confirmatory factor analysis was used to analyze the 
structure of the STAXI in the present study. The items were entered in the factor analysis and they were modeled to represent the three factors. Results revealed an acceptable fit of the model $\left(\chi^{2}=449.70, d f=367, p<.01\right)$. The absolute as well as the relative fit indices showed that the three factor model fit the data acceptably: RMSEA $=0.04, \mathrm{CFI}=0.93$, AGFI $=0.81$. While RMSEA and CFI where within the acceptable range, the AGFI was below the recommended value 0.90 (Hooper, Coughlan, \& Mullen, 2008).

In a second step the factor structure of the mindfulness measure was analyzed with a confirmatory factor analysis. In the American version Greco et al. (2011) preferred a one-dimensional structure against a two-dimensional one, because of the clearer interpretability. In the present study the confirmatory factor analysis revealed a good fit of the single factor model. All items were modeled to form one factor and the fit indices supported the idea of a one-dimensional scale structure $\left(\chi^{2}=41.79, d f=26, p=.03\right.$, RMSEA $=$ 0.06, $\mathrm{CFI}=0.94$, AGFI $=0.91$ ).

As we used the Emotion Regulation Checklist (Shields \& Cicchetti, 1997) for the first time in a German sample we also analyzed the structure of the questionnaire with a confirmatory factor analysis. The analysis revealed a poor fit between the postulated two factor model and the data $\left(\chi^{2}=515.22, d f\right.$ $=229, p<.01, \mathrm{RMSEA}=0.09, \mathrm{CFI}=0.60$, AGFI =0.71). The fit indices did not fall in an acceptable range. The inspection of modification indices was not useful to improve the model; therefore it was decided to conduct an exploratory factor analysis with principal axis factoring and varimax rotation. In the exploratory factor analysis according to the scree test criterion two factors were extracted. The factors did largely reflect the structure that was suggested by Shields and Cicchetti (1997), but there were also some meaningful differences. The first factor contained items assessing lability and difficulties in emotion regulation. The factor loadings ranged between .30 and .69. The items that formed the second factor can be described as assessing a well working emotion regulation (factor loadings between .28 and .65). Two items could not be assigned to one of the two factors as they had comparably high loadings on both factors ("[My child] is a cheerful child." and "[My child] can modulate excitement in emotionally arousing situations.") and one item could not be assigned to one of the factors as it had no factor loading $>.25$ ("[My child] seems sad or listless."). Therefore it was decided to omit these three items from all further analyses. The major difference to the structure that had been suggested by Shields and Cicchetti (1997) can be found with respect to items loading negatively on either of the factors. In the present sample mainly these items switched between the factors compared to the original version of Shields and Cicchetti (1997). 


\section{Descriptive Statistics}

After the structure of the scales was clarified the sumscores and standard deviations were computed. The values can be found in Table 1. Moreover, it was analyzed how many children were above or below the critical value indicating serious conduct problems according to the SDQ (Woerner et al., 2002). The values 0 - 2 indicate that a child has no conduct problems and a value of 3 indicates that the parent rating is at the border. Values above 4 indicate that a child has conduct problems. In the present sample 165 children did not have conduct problems, 13 children were rated as borderline and 23 children had conduct problems.

Table 1.Descriptive Statistics of the Scales

\begin{tabular}{llllll}
\hline \multicolumn{1}{c}{ Scale } & $\begin{array}{l}\text { No. of } \\
\text { items }\end{array}$ & Min & Max & $\boldsymbol{M}$ & SD \\
\hline Child ratings & 11 & 11 & 30 & 19.99 & 4.07 \\
$\quad$ Anger In & 10 & 10 & 29 & 14.83 & 4.71 \\
Anger Out & 8 & 8 & 24 & 17.37 & 3.69 \\
$\quad \begin{array}{l}\text { Anger Control } \\
\text { Mindfulness }\end{array}$ & 10 & 10 & 50 & 34.81 & 7.02 \\
$\begin{array}{c}\text { Parent ratings } \\
\text { Emotion }\end{array}$ & 9 & 16 & 36 & 28.53 & 3.95 \\
$\begin{array}{l}\text { regulation } \\
\text { Lability }\end{array}$ & 11 & 13 & 33 & 19.99 & 4.34 \\
$\quad \begin{array}{l}\text { Conduct } \\
\text { Problems }\end{array}$ & 5 & 0 & 8 & 1.52 & 1.61 \\
\hline
\end{tabular}

In addition the internal consistencies of the scales were computed. For the scales of the STAXI the Cronbach's Alphas were fairly good (Anger In: $\alpha$ $=.71$, Anger Out: $\alpha=.87$, Anger Control: $\alpha=.78$ ). The internal consistency of the CAMM was $\alpha=.72$ and is therefore somewhat lower that the value reported by Greco et al. (2011) for the American version $(\alpha=.80)$, but the value was completely in accordance with the value reported by de Bruin, Zijlstra, and Bögels (2013) for the use of the scale in the Netherlands. The two scales assessing children's emotion regulation skills via parental report showed acceptable internal consistencies as well (emotion regulation: $\alpha=.64$, lability: $\alpha=.78$ ). The five items assessing conduct problem via parent rating also had an acceptable internal consistency $(\alpha=.65)$.

\section{Correlations between the Scales}

Bivariate correlations were computed to analyze the relations between the scales. The results can be found in Table 2. First the correlations between anger expression and mindfulness in children will be reported. Significant negative correlations ranging between $r=-.15$ and $r=-.26$ could be found for mindfulness and all anger expression. Children with higher levels of mindfulness showed their anger less outwardly and they also hided their anger 
less. However, these children did also put less effort in controlling their anger. The relation between mindfulness and parental reports of emotion regulation were computed as well. Mindfulness was significantly negatively related to regulation difficulties $(r=-.25, p<.01)$, but it was not related to adaptive emotion regulation reported by parents $(r=-.05, p=.49)$.

Table 2. Correlations of the Scales

\begin{tabular}{|c|c|c|c|c|c|c|}
\hline & 2. & 3. & 4. & 5. & 6. & 7. \\
\hline 1. Anger In & -.01 & $.32 * *$ & $-.26 * *$ & .06 & -.01 & -.02 \\
\hline 2. Anger Out & & $-.35 * *$ & $-.33 * *$ & .01 & $.35^{* *}$ & $.37 * *$ \\
\hline 3. Anger Control & & & $-.15^{*}$ & .02 & -.01 & -.04 \\
\hline 4. Mindfulness & & & & -.05 & $-.25 * *$ & $-.25 * *$ \\
\hline 5. Emotion Regulation & & & & & $-.15^{*}$ & $-.24 * *$ \\
\hline 6. Lability & & & & & & $.66 * *$ \\
\hline 7. Conduct Problems & & & & & & \\
\hline
\end{tabular}

Note. $* p<.05, * * p<.01$.

With respect to the correlations between child reported anger expression and parental reports of emotion regulation only the Anger Out scale of the STAXI was moderately but significantly correlated with regulation difficulties reported by parents $(r=.35, p<.01)$. Anger In and Anger Control were not related to parental reports of emotion regulation. Surprisingly, no correlations between parental reports of an adaptive emotion regulation and child reports of anger expression could be detected.

\section{Mindfulness and Anger Expression as Predictors of Behavioral Problems}

To assess the predictive power of mindfulness and anger expression for behavioral problems, linear regression analyses were computed. It was decided to analyze the predictive effects of child reported mindfulness and anger expression. In a first analysis with child reported indicators mindfulness was used as predictor of conduct problems $\left(R^{2}=.06, \beta=-.25, p<.01\right)$ and it could be shown that it was a significant predictor of conduct problems. In a next step the three anger expression scales (Anger Out, Anger In, Anger Control) were added as predictors to the regression model and the effect of mindfulness diminished $(\beta=-.14, p=.06)$. Anger Out was the only significant predictor of conduct problems $(\beta=.34, p<.01)$. This regression model explained $16 \%$ of variance and was statistically significant $(p<.01)$.

\section{Discussion}

In the present study we investigated the relationship between mindfulness, anger expression, emotion regulation, and conduct problems in children. For this purpose, parent as well as child ratings were used and the psychometric properties of the scales were tested in a German sample. The 
dimensional structure of the Child and Adolescent Mindfulness Measure (CAMM; Greco et al., 2011) and the STAXI (Seip, 2010) could be replicated. The factor structure of the ERC (Shields \& Cicchetti, 1997) differed significantly from the original version. The internal consistencies of all scales fell in an acceptable range. This indicates that the scales can be used for German speaking participants. In future studies more information about predictive validity as well as construct validity should be gathered. The CAMM (Greco et al., 2011) has already previously been translated to other languages, such as Dutch (de Bruin et al., 2013) or Portuguese (Cunha, Galhardo, \& Pinto-Gouveia, 2013). In those translations also a single factor structure was extracted.

The descriptive statistics show that the children in our sample had a rather high level of mindfulness. They use anger control strategies rather than internalizing or externalizing their anger. The parent rating of conduct problems (Woerner et al., 2002) revealed that only a few children showed a borderline or abnormal level of conduct problems.

As expected, there were negative correlations between mindfulness and anger expression of children. The strongest negative correlation was found for mindfulness and the strategy to show anger verbally or physically (Anger Out). Children who have lower levels of mindfulness express their anger more often in an externalizing way. This finding fits to the assumptions of the Process Modell of Emotion Regulation (Gross, 2002), which assumes that antecedent-focused emotion regulation strategies are precursors of emotion response tendencies. Mindfulness might therefore be important with respect to antecedent processes. Hayes and Feldman (2004) as well as Chambers, Gullone, and Allen (2009) suggested in their reviews that mindfulness can enable individuals to deal with their emotions in a healthy way. Nonetheless, Chambers et al. (2009) concluded that the exact relation between mindfulness and emotion regulation strategies remains unclear. However, it can be assumed that a higher level of mindfulness might improve the handling of emotions as it alters the interpretation and acceptance of emotions and can thus alter response-focused emotion regulation (Hofmann \& Asmundson, 2008). High levels of mindfulness would therefore be related to lower levels of anger expression (Anger Out). This mechanism would also explain why children with higher levels of mindfulness have a lower need to suppress their anger (Anger In).

Parental reports of emotion regulation were not correlated to mindfulness and only for lability and Anger Out there was a correlation between the emotion regulation ratings of parents and children. Even though these findings were somewhat surprising, they are consistent with the findings of Hourigan, Goodman, and Southam-Gerow (2011), who could demonstrate that child and parent ratings of emotion regulation differ more when internal 
processes are measured. As parents normally cannot directly observe mindfulness, Anger In, and Anger Control this might explain the insignificant results. This assumption is supported by the significant positive correlation between Anger Out and parental reports of lability. Showing anger verbally or physically is easily observable for parents and can thus clearly be used as an indicator of deficits in emotion regulation for the parental report.

The present results reflect findings that have previously been published and they support the assumption that mindfulness, anger expression and emotion regulation are important aspects that influence child behavior (Eisenberg et al., 2010; Semple, Lee, Rosa, \& Miller, 2010). These findings can have important implications for teachers and practitioners as they underpin the importance of programs fostering mindfulness or emotion regulation (Hill \& Updegraff, 2012). Moreover, our results showed that the relation of mindfulness and conduct problems is mediated by anger expression. Therefore it can be assumed that mindfulness is an important precursor of emotion expression and an early fostering of mindfulness is beneficial for a better development of emotion regulation skills. Mindfulness as a multidimensional construct that includes the facets accepting emotions without judging them and being aware of the present moment (Greco et al., 2011) can be helpful for a healthy social and academic development of children (Rempel, 2012). The effects of mindfulness are far reaching as mindfulness is for instance reversely related to stress, rumination and catastrophizing (de Bruin et al., 2013), and even relations to neurophysiological indicators such as cortisol levels were found in previous studies (Brand, Holsboer-Trachsler, Naranjob, \& Schmidt, 2012).

\section{Limitations}

Due to the assessment of emotion regulation skills and conduct problems via parent report these scales correlated stronger with each other than with child rated mindfulness or anger expression. For future studies an additional self-rating of conduct problems or a more objective observational measure would be helpful.

Another important limitation regards the sample of children. As we asked children in elementary school, they have a rather low rate of conduct problems that are mainly not clinically relevant. It would be of great interest to repeat our study with a sample of children attending special needs education classes or displaying a higher level of problem behavior.

\section{Implications}

Taken together, this study supports the idea that the relation between mindfulness and behavior is mediated by emotion regulation. This assumption was also proposed by other researchers (Gratz \& Tull, 2010; Hill \& Updegraff, 
2012). However, the major focus was put on mindfulness as a dispositional characteristic. Therefore no conclusions can be drawn with respect to programs fostering mindfulness. Even though there is evidence that mindfulness trainings can enhance mindfulness in children (Burke, 2010), the mediation hypothesis of emotion regulation should be investigated for the effects of mindfulness trainings on child problem behavior as well. Furthermore, it is important to keep in mind that mindfulness is not the only possibility to enhance emotion regulation skills and reduce problem behavior. According to the Process Modell of Emotion Regulation (Gross, 2002), there are five important factors that influence the regulation of emotions. It should therefore be beneficial to develop programs that do not only focus on mindfulness but that address the complete process of emotion regulation, including for instance situation selection as well as regulation of behavioral responses. Nevertheless, mindful emotion regulation is a resource that allows children to be aware of the present moment and to accept feelings nonjudgmentally and it enables children to choose reactions to emotions more consciously (Chambers et al., 2009).

\section{References:}

1. Arbuckle, J. L. (2013). IBM SPSS Amos 22 User's Guide. Meadville: Amos Development Corporation.

2. Baer, R. A. (2003). Mindfulness training as a clinical intervention: A conceptual and empirical review. Clinical psychology: Science and practice, 10, 125-143.

3. Baer, R. A., Smith, G. T., Hopkins, J., Krietemeyer, J., \& Toney, L. (2006). Using self-report assessment methods to explore facets of mindfulness. Assessment, 13, 27-45.

4. Brand, S., Holsboer-Trachsler, E., Naranjo, J. R., \& Schmidt, S. (2012). Influence of mindfulness practice on cortisol and sleep in longterm and short-term meditators. Neuropsychobiology, 65, 109-118.

5. Burke, C. A. (2010). Mindfulness-based approaches with children and adolescents: A preliminary review of current research in an emergent field. Journal of Child and Family Studies, 19, 133-144.

6. Chambers, R., Gullone, E., \& Allen, N. B. (2009). Mindful emotion regulation: An integrative review. Clinical psychology review, 29, 560-572.

7. Cole, P. M., Zahn-Waxler, C., Fox, N. A., Usher, B. A., \& Welsh, J. D. (1996). Individual differences in emotion regulation and behavior problems in preschool children. Journal of Abnormal Psychology, 105, 518-529.

8. Cunha, M., Galhardo, A., \& Pinto-Gouveia, J. (2013). Child and Adolescent Mindfulness Measure (CAMM): Estudo das 
Características Psicométricas da Versão Portuguesa. Psicologia: Reflexão e Crítica, 26, 459-468.

9. de Bruin, E. I., Zijlstra, B. J., \& Bögels, S. M. (2013). The meaning of mindfulness in children and adolescents: Further validation of the Child and Adolescent Mindfulness Measure (CAMM) in two independent samples from the Netherlands. Mindfulness, 1-9.

10. Eisenberg, N., Spinrad, T. L., \& Eggum, N. D. (2010). Emotion-related self-regulation and its relation to children's maladjustment. Annual review of clinical psychology, 6, 495-525.

11. Evans, S., Ferrando, S., Findler, M., Stowell, C., Smart, C., \& Haglin, D. (2008). Mindfulness-based cognitive therapy for generalized anxiety disorder. Journal of anxiety disorders, 22, 716-721.

12. Garnefski, N., Rieffe, C., Jellesma, F., Terwogt, M. M., \& Kraaij, V. (2007). Cognitive emotion regulation strategies and emotional problems in 9-11-year-old children. European Child \& Adolescent Psychiatry, 16, 1-9.

13. Gratz, K. L., \& Tull, M. T. (2010). Emotion regulation as a mechanism of change in acceptance- and mindfulness-based treatments. In R. A. Baer (Ed.), Assessing Mindfulness and Acceptance Processes in Clients: Illuminating the Theory and Practice of Change (pp. 107133). Oakland: New Harbinger Publications.

14. Greco, L. A., Baer, R. A., \& Smith, G. T. (2011). Assessing mindfulness in children and adolescents: Development and validation of the Child and Adolescent Mindfulness Measure (CAMM). Psychological Assessment, 23, 606-614.

15. Gross, J. J. (2002). Emotion regulation: Affective, cognitive, and social consequences. Psychophysiology, 39, 281-291.

16. Harnett, P. H., \& Dawe, S. (2012). Review: The contribution of mindfulness-based therapies for children and families and proposed conceptual integration. Child and adolescent mental health, 17, 195208.

17. Hayes, A. M., \& Feldman, G. (2004). Clarifying the construct of mindfulness in the context of emotion regulation and the process of change in therapy. Clinical Psychology: Science and Practice, 11, 255262.

18. Hill, C. L., \& Updegraff, J. A. (2012). Mindfulness and its relationship to emotional regulation. Emotion, 12, 81-90.

19. Hofmann, S. G., \& Asmundson, G. J. (2008). Acceptance and mindfulness-based therapy: New wave or old hat? Clinical psychology review, 28, 1-16.

20. Holtappels, H. G., Heitmeyer, W., Melzer, W., \& Tillmann, K.-J. (Eds.) (2009). Forschung über Gewalt an Schulen. 
Erscheinungsformen und Ursachen, Konzepte und Prävention [Research on violence at schools. Form, cause, concepts and prevention]. Weinheim: Juventa.

21. Hooper, D., Coughlan, J., \& Mullen, M. R. (2008). Structural equation modelling: Guidelines for determining model fit. The Electronic Journal of Business Research Methods, 6, 53-60.

22. Hourigan, S. E., Goodman, K. L., \& Southam-Gerow, M. A. (2011). Discrepancies in parents' and children's reports of child emotion regulation. Journal of experimental child psychology, 110, 198-212.

23. Izard, C. E. (2009). Emotion theory and research: Highlights, unanswered questions, and emerging issues. Annual review of psychology, 60, 1-25.

24. Kabat-Zinn, J. (1994). Wherever you go, there are you: Mindfulness meditation in everyday life. New York: Hyperion.

25. Kabat-Zinn, J., Massion, A. O., Kristeller, J., Peterson, L. G., Fletcher, K., Pbert, L., Linderking, W., \& Santorelli, S. F. (1992). Effectiveness of a meditation-based stress reduction program in the treatment of anxiety disorders. American Journal of Psychiatry, 149, 936-943.

26. Kerr, M. A., \& Schneider, B. H. (2008). Anger expression in children and adolescents: A review of the empirical literature. Clinical Psychology Review, 28, 559-577.

27. Lee, J., Semple, R. J., Rosa, D., \& Miller, L. (2008). Mindfulnessbased cognitive therapy for children: Results of a pilot study. Journal of Cognitive Psychotherapy, 22, 15-28.

28. Linehan, M. M. (1993). Cognitive-behavioral treatment of borderline personality disorder. New York: Guilford Press.

29. Ma, S. H., \& Teasdale, J. D. (2004). Mindfulness-based cognitive therapy for depression: replication and exploration of differential relapse prevention effects. Journal of consulting and clinical psychology, 72, 31-40.

30. MacDermott, S. T., Gullone, E., Allen, J. S., King, N. J., \& Tonge, B. (2010). The emotion regulation index for children and adolescents (ERICA): a psychometric investigation. Journal of Psychopathology and Behavioral Assessment, 32, 301-314.

31. McLaughlin, E. M. (2010). The Relationship Between Dispositional Mindfulness and Emotion Regulation in Children (Dissertation thesis). Available from ProQuest Dissertations and Theses database. (UMI No. 3412745)

32. Petermann, F. \& Wiedebusch, S. (2008). Emotionale Kompetenz bei Kindern [Emotional competence in children]. Göttingen: Hogrefe.

33. Rempel, K. D. (2012). Mindfulness for children and youth: A review of the literature with an argument for school-based implementation. 
Canadian Journal of Counselling \& Psychotherapy/Revue Canadienne de Counseling et de Psychothérapie, 46, 201-220.

34. Schwenkmezger, P., Hodapp, V., \& Spielberger, C. (1992). Das StateTrait-Ärgerausdrucks-Inventar (STAXI) [State-Trait Anger Expression Inventory (STAXI)]. Bern: Huber.

35. Seip, M. (2010, September). Zeigen oder nicht zeigen? Entwicklung eines Verfahrens zur Erfassung von Ärgerreaktionen bei Kindern und Jugendlichen. Poster presented at the 47. Kongress der Deutschen Gesellschaft für Psychologie. Bremen.

36. Semple, R. J., Lee, J., Rosa, D., \& Miller, L. F. (2010). A randomized trial of mindfulness-based cognitive therapy for children: Promoting mindful attention to enhance social-emotional resiliency in children. Journal of Child and Family Studies, 19, 218-229.

37. Shields, A., \& Cicchetti, D. (1997). Emotion regulation in school-age children: The development of a new criterion Q-sort-scale. Developmental Psychology, 33, 906-916.

38. Stegge, H., \& Meerum Terwogt, M. M. (2007). Awareness and regulation of emotion in typical and atypical development. In J. J. Gross (Ed.), Handbook of emotion regulation, (pp. 269-286). New York: Guilford Press.

39. Teper, R., Segal, Z. V., \& Inzlicht, M. (2013). Inside the Mindful Mind How Mindfulness Enhances Emotion Regulation Through Improvements in Executive Control. Current Directions in Psychological Science, 22, 449-454.

40. van der Ende, J., Verhulst, F. C., \& Tiemeier, H. (2012). Agreement of informants on emotional and behavioral problems from childhood to adulthood. Psychological Assessment, 24, 293-300.

41. Woerner,W., Becker, A., Friedrich, C., Klasen, H., Goodman, R., \& Rothenberger, A. (2002). Normierung und Evaluation der deutschen Elternversion des Strengths and Difficulties Questionnaire (SDQ): Ergebnisse einer repräsentativen Felderhebung [German version of the SDQ]. Zeitschrift für Kinder- und Jugendpsychiatrie und Psychotherapie, 30, 105-112.

42. Wright, S., Day, A., \& Howells, K. (2009). Mindfulness and the treatment of anger problems. Aggression and Violent Behavior, 14, 396-401.Macmillan. 